\title{
On Current Situation and Countermeasures of Professional Health Team in 104 Town Health Centers
}

\author{
Sulan Long ${ }^{1}$, Fengyun Long ${ }^{2}$ *, Ling $\mathrm{Ma}^{3}$ \\ ${ }^{1}$ Department of Nursing, Science and Technology College of Jiangxi University of Traditional Chinese \\ Medicine, Nanchang Jiangxi, 330004, China \\ ${ }^{2}$ Department of Anesthesiology, Subei People's Hospital of Jiangsu, Yangzhou Jiangsu, 225001, China \\ ${ }^{3}$ B-ultrasonic, Yangzhou Maternal and Child Health Hospital, Yangzhou Jiangsu, 225002, China \\ *Corresponding author
}

Keywords: town health center; health workers; current situation; countermeasures.

\begin{abstract}
Town health centers play a pivotal role in rural three-level health service network. Questionnaire survey and interview are combined in this paper to investigate current situation of health workers in 104 town health centers of Jiangxi Province. The results show that, the major problems of health workers include insufficient number, inverse proportion of doctors and nurses and obvious shortage of nursing workers, young age structure, low educational background and job title, low professional quality and the whole quality of health workers. Based on the analysis of these problems, the following countermeasures are proposed: to create a loose talent environment; to improve job title appraisal standards and staff treatment; to perfect social security mechanism and solve staffs' housing difficulties; and to establish the talent training mode adapting to rural health service demand.
\end{abstract}

\section{Object and method}

\subsection{Object of study}

Under the support of Committee of Education, Science, Culture, Health and Sports of the Chinese People's Political Consultative Conference (CPPCC) and the participation of relevant country and municipal committees of CPPCC, this research was organized. There are 1660 town health centers in Jiangxi province. Based on considering the coverage of each district and city, the central health centers and general health centers of some countries (or districts and cities) were sampled according to the proper proportion, and 104 town health centers were chosen in total. Health workers of the 104 health centers were chosen as the object of study.

\subsection{Research method}

Epidemiology inventory survey method was used to carry out stratified sampling according to three levels of economic and social development level of Jiangxi Province: good, moderate and poor. Among 1660 town health centers, 104 were chosen as the research units, including 54 central health centers and 50 general health centers. Then, stratified random sampling method was applied to abstract 10 health workers (including 4 doctors, 3 nurses and 3 health workers) as the respondents, and the questionnaires were distributed to gain the information. Finally, all investigation data were inputted in the computer to establish the database after the data were checked and corrected. SPSS19.0 software was used to conduct statistical analysis of relevant indexes. 


\section{Analysis of research results}

\subsection{Basic information of workers in 104 town health centers (mean in 2014-2016)}

Table 1. Basic information of workers in town health centers

\begin{tabular}{|c|c|}
\hline (Mean) & $2014-2016$ \\
\hline Total number & 35.27 \\
\hline Authorized staffs & 27.95 \\
\hline On-duty workers & 32.42 \\
\hline Mean total number in central health centers & 48.7 \\
\hline Authorized staffs in central health centers & 38.18 \\
\hline On-duty workers in central health centers & 44.62 \\
\hline Total number in general health centers & 20.75 \\
\hline Authorized staffs in general health centers & 16.89 \\
\hline On-duty workers in general health centers & 19.25 \\
\hline
\end{tabular}

It is known from the survey data that, the number in general health centers is significantly less than that of central health centers; the total number, number of authorized staffs and number of on-duty workers have the growing trend in the three years; the quantity growth in general health centers is slightly higher than that of central health centers. The total number of central health centers is significantly higher than that of general health centers (2.3 times on the average). The workers employed beyond the staff quota mainly concentrate in the central health centers, and the overstrength in central health centers is serious. The health workers in the health centers increase less in the three years, which indicates that the recruitment difficulty of health centers is large. In addition, unreasonable proportion of doctors and nurses generally exists in town health centers ${ }^{[2]}$. In the survey, the mean proportion of doctors and nurses in the town health centers is 1:0.69. It still has the gap with the standard specified by the Ministry of Health (1:1 in rural area and 1:2 in urban area). Reasonable configuration of proportion of doctors and nurses is the key to meeting the needs of medical and health services and enhancing health service quality. According to the data, the proportion of doctors and nurses in Japan and UK is above 1:4. The proportion of doctors and nurses in Norway and Canada exceeds 1:6, while the proportion of doctors and nurses in China is less than $1: 1^{[3]}$.

\subsection{Variation trend of workers in health centers (mean in 2014-2016)}

Table 2. Variation trend of workers in health centers

\begin{tabular}{cccc}
\hline (Mean) & $\mathbf{2 0 1 4}$ & $\mathbf{2 0 1 5}$ & $\mathbf{2 0 1 6}$ \\
\hline Total number in health centers & 33.44 & 35.38 & 37.67 \\
Vacancies & 5.25 & 6.44 & 7.6 \\
On-duty technical workers & $82.52 \%$ & $84.22 \%$ & $83.18 \%$ \\
Temporarily employed workers & $29.67 \%$ & $30.28 \%$ & $32.47 \%$ \\
Certified doctors and assistants & 11.13 & 11.74 & 12.31 \\
\hline
\end{tabular}

It is known from the survey data that, the proportion of professional technical workers and temporality employed workers presents the rising trend in the three years. 104 town health centers served 39904 people on the average. The central health centers served 55568 people on the average. General central health centers served 22461 people on the average. The number of health workers per 1000 population is $0.95,1.02$ and 1.08 respectively in the three years. The number of health workers per 1000 population in central health centers is $1.08,1.15$ and 1.22 respectively, higher than 0.73 , 0.80 and 0.85 in general health centers. The proportion of doctors and nurses is 1:0.68, 1:0.68 and 1:0.70 respectively. The proportion of doctors and nurses in central health centers is 1:0.75, 1:0.77 and 1:0.78 respectively. The proportion of doctors and nurses in central health centers is 1:0.53, 1:0.52 and 1:0.53 respectively.

This research shows that, age structure change of health workers in 104 town heath centers in 2014-2016 is not obvious. For both central health centers and general health centers, health workers are generally young, with the age of 30-50. The age structure is basically rational. The number of 
health workers below 30 years old has the slowly increasing trend. The number of health workers with the age between 30 and 50 presents the stable fluctuation in the small range. The number of health workers above 50 years old slowly decreases. This conforms to the fact that the technical force of town health centers is young and middle-aged workers, and the doctors and nurses become younger in average age. This may be related to the enhanced medical reform force in recent years and preferential policy for grassroots medical institutions.

The problem of education background has been a bottleneck troubling the development of town health centers. The survey results show that, among the health workers in 104 town health centers, the health workers with the education background of technical secondary school and below still account for 53\% 58\%. Medicine is a systematic knowledge hierarchy. If there is short of sufficient learning time and systematic knowledge training, medical students impossibly become qualified medical workers. Seeing from the development trend of current medicine education, high-quality and qualified doctors must go through special training for 8-11 years and own the master degree or doctor degree. In current stage, the rural area impossibly reaches the above requirement, but systematic and standard undergraduate or post-secondary education may be achieved. The survey results show that health workers in 104 town health centers mainly own the primary job title, as high as 65\%. The proportion of health workers with vice high job title and above is extremely low, only about $1 \%$. What is worth mentioning that, among these health workers, a large number of them engage in medical and health work for a long time, but they have no professional technical title (about $13 \%$ on the average).

\subsection{Age distribution of health workers (mean in 2014-2016)}

Table 3. Age distribution of health workers in town health centers

\begin{tabular}{lccc}
\hline Below 30 & Above 30 & Above 50 \\
\hline & $\mathbf{2 0 1 4}$ & & \\
Central health centers & $39.80 \%$ & $50.18 \%$ & $10.03 \%$ \\
General health centers & $38.73 \%$ & $46.83 \%$ & $14.43 \%$ \\
& $\mathbf{2 0 1 5}$ & & \\
Central health centers & $39.62 \%$ & $50.39 \%$ & $9.99 \%$ \\
General health centers & $40.14 \%$ & $46.36 \%$ & $13.50 \%$ \\
& $\mathbf{2 0 1 6}$ & & \\
Central health centers & $39.76 \%$ & $51.18 \%$ & $9.07 \%$ \\
General health centers & $41.36 \%$ & $46.02 \%$ & $12.61 \%$ \\
\hline
\end{tabular}

It is known from the survey data that, age structure of two kinds of health centers has significant differences in the three years. In particular, the proration of health workers above 30 is large in the three years, and the age structure presents the young trend, but chi-square test result indicates the distribution of health workers at different age groups has no significant difference. The analysis of the same age group in different years shows that in 2014-2016, the proportions of health workers below 30 are $39.49 \%$, $39.77 \%$ and $40.20 \%$ respectively, and the mean growth rate is slow. The proportions of health workers above 50 are $311.29 \%, 11.01 \%$ and $10.05 \%$ respectively, and the mean growth rate is also slow. The proportion of health workers with the age between 30 and 50 is the largest, up to $49.22 \%, 49.22 \%$ and $49.75 \%$ respectively. As times goes on, age structure shows the young trend. 


\subsection{Education background distribution of health workers (mean in 2014-2016)}

Table 4. Education background distribution of health workers in town health centers

\begin{tabular}{lcll}
\hline & $\mathbf{2 0 1 4}$ & $\mathbf{2 0 1 5}$ & $\mathbf{2 0 1 6}$ \\
\hline Technical secondary & & & \\
school and below & $58.44 \%$ & $56.11 \%$ & $53.43 \%$ \\
College degree & $35.82 \%$ & $37.35 \%$ & $38.60 \%$ \\
Bachelor degree & $5.71 \%$ & $6.50 \%$ & $7.94 \%$ \\
\hline
\end{tabular}

It is known from the survey data that, the distribution of health workers with different education background has significant differences, and education background is generally low. Based on time analysis, education background structure in the two kinds of health centers has no significant changes in the three years. Education background of health workers in 104 town health centers is generally low. In the three years, the health workers with the degree of technical secondary school and below account for over a half. The mean growth rates of health workers with the degree of technical secondary school and below in central health workers and general health centers are 2.76 and 0.74 respectively in the three years, with the total mean growth rate of 2.19. The mean growth rates of health workers with the degree of junior college in central health workers and general health centers are 8.80 and 7.20 respectively in the three years, with the total mean growth rate of 7.94 . The mean growth rates of health workers with bachelor degree in central health workers and general health centers are 18.22 and 15.44 respectively in the three years, with the total mean growth rate of 17.53.

\subsection{Job title distribution of health workers (mean in 2014-2016)}

Table 5. Job title distribution of health workers in town health centers

\begin{tabular}{lrrl}
\hline & $\mathbf{2 0 1 4}$ & $\mathbf{2 0 1 5}$ & $\mathbf{2 0 1 6}$ \\
\hline \multicolumn{2}{l}{$\begin{array}{l}\text { Proportion of health workers } \\
\text { without job title } \\
\text { Primary job title }\end{array}$} & & \\
Vice high job title and above & $12.05 \%$ & $13.43 \%$ & $13.41 \%$ \\
\hline
\end{tabular}

It is known from the survey data that, in 2014-2016, job title distribution of health workers in both central health centers and general health centers has differences in the three years. The proportions of health workers with intermediate job title and above in central health centers $(23.36 \%, 22.02 \%$ and $23.23 \%$ respectively) are higher than that of general health centers (18.85\%, $18.08 \%$ and $18.51 \%$ respectively). The proportions of health workers without job title in central health centers $(15.58 \%$, $16.14 \%$ and $15.72 \%$ respectively) are higher than that of general health centers (10.6\%, $12.29 \%$ and $12.51 \%$ respectively). The education background structure is generally low, and the whole job title structure improves slightly.

The job title structure of health workers in the 104 town health centers is mainly primary job title. The three-year survey result shows that, the proportion of health workers with primary job title is as high as about $65 \%$, and the big change is not seen. The structure of health workers with intermediate job title does not improve, either (about 20\% in the three years). The proportion of health workers with vice high job title and above is very small $(1.14 \%, 1.01 \%$ and $0.98 \%$ respectively in the three years). About the number of health workers without job title, the mean growth rates of central health centers and general health centers in the three years are 11.76 and 4.30 respectively, with total growth rate of 9.07. About the number of health workers with primary job title, the mean growth rates of central health centers and general health centers in the three years are 4.82 and 4.09 respectively, with total growth rate of 4.61. About the number of health workers with intermediate job title, the mean 
growth rates of central health centers and general health centers in the three years are 5.87 and 3.65 respectively, with total growth rate of 5.31 .

\section{Suggestions}

\subsection{To create loose talent environment}

Firstly, it is required to establish talent cycle mechanism by combining practical conditions of each village, formulate the incentive measures and create the good living and working environment. If necessary, talent team construction in town health centers can be listed in the work assessment criterion for main leaders of relevant functional departments and presidents of health centers. Secondly, health centers should formulate the talent training plan. For example, health centers should specify the duties of those who are arranged to further study, sign the contract with them and strive to let them bring new technologies and new treatment methods and form a characteristic specialty. Thirdly, it is required to start from the practical conditions and give more preferential policies to those medical workers with unique skills.

\subsection{To improve job title evaluation standard and staff treatment}

To stabilize technical talent team of health centers, practical life and treatment problems should be solved to exempt their worries. The suggestions are as follows: (1) to improve performance salary system and practical treatment; (2) to actively seek the new thought of job title appraisal for town health centers. Based on this survey, there are mainly two opinions on job title appraisal for town health centers. The first one is to reduce appraisal standard, i.e. to reduce or cancel the number and grade of papers and scientific research topics; to enjoy the corresponding salary and treatment only in the province, local place or the unit. The other one is not to reduce the standard. In other words, the appraisal standard is same, but for the workers who fail in the appraisal, their salary and allowance level may increase according to their years of working and assessment result; to solve employment problem for those with job title qualification.

\subsection{To perfect social security mechanism and solve housing problem for staffs}

As social security mechanism continues to improve in China, all kinds of security mechanisms should be improved for health workers in town health centers, such as children's education, children's employment and housing security. This survey found that, the 104 town health centers failed to solve housing problem for staffs; the service houses were occupied for accommodation; the living conditions of medical workers in branches were poor. These phenomena generally exist everywhere. The housing problem also becomes a bottleneck hindering the development of health centers. The suggestions are as follows: (1) to provide low-rent houses. Certain proportion of low-rent houses may be taken from the houses built by the government for workers in town health workers; (2) to build the department for staffs. Health centers may invest or introduce social funds to construct the department. The staffs need to pay certain rent monthly. For the former, the rent is undertaken by workers (may be deducted form the salary). For the latter, the rent is jo9intly undertaken by the health centers and workers (according to certain proportion); (3) the government, the unit and individuals jointly invest to build the makeshift houses. After staffs live in the makeshift houses, they may live for a long time as long as they work there, but they have no property right. If they leave their posts, the unit will return the fund for house building to them and take the houses back.

\subsection{To train medical students and reform full-time education}

In medical education which aims to cultivate medical workers for grassroots medical institutions, it is required to adjust and compress periods, expand the scope of specialty, enhance social adaptiveness of specialty and, pay attention to cultivation of basic medical theories, basic knowledge and basic skills, strengthen ability training and clinical thinking ability cultivation with the key point of clinical skills and attach great importance to medical students' development in the aspects of 
knowledge, ability, comprehensive quality and innovative thinking. Meanwhile, medical colleges should break through traditional training mode, really train the new health talents who can go to grassroots, be useful and be retained and explore the new pattern of medical education with Chinese characteristics.

\section{Conclusion}

Town health centers as grassroots medical and health institutions play a very important role in rural areas of China. They directly shoulder the glorious mission of providing medical and health care services for rural residents. As the reform and opening-up policy deepens and develops continuously, the development of town health centers in Jiangxi Province has gained great progress, but there are still various problems, such as lack of health workers; inverse proportion of doctors and nurses and obvious shortage of nursing workers; young age structure; low educational background and job title; low professional quality and the whole quality of health workers. With the implementation of new medical reform package, how to develop town health centers is an important topic which deserves in-depth researches.

\section{Acknowledgement}

2017 science and technology planning project of Health and Family Planning Commission of Jiangxi Province Research On Current Situation and Countermeasures of Professional Health Team in Town Health Centers of Jiangxi Province, project No.: 20175545.

\section{References}

[1] Zhou Chunlin, Research on Current Situation of Rural Health Human Resources in Xianning City, Shandong: Shandong University, 2010.

[2] Long Sulan, Huang Helang, Wu Yifeng et al., Current Situation and Influencing Factors of Health Human Resource in Chinese Town Health Centers, Chinese journal of Public Health, 2012, 28 (4): 558-559.

[3] Zhao Jing, Analysis on Current Situation of Health Human Resource of Grassroots Medical Organizations in Jilin Province, Jilin: Jilin University, 2010. 